\title{
Frequency of Monthly Ejaculation at Sexual Intercourse, DNA Fragmentation Index and Fertilization Rate among Sperm Donors and Fertility-Challenged Men in Sub-Saharan Africa: Paper 2
}

\author{
Abayomi B. Ajayi', Bamgboye M. Afolabi ${ }^{2}$, Victor D. Ajayi' ${ }^{1}$ Ifeoluwa 0. Oyetunji', \\ Adedamilola Atiba1, Seun Saanu', Ayodeji T. Adeoye'1, Joy Ehichioya1, Ibukun I. Ayelehin1 \\ ${ }^{1}$ Nordica Fertility Center, Lagos, Nigeria \\ ${ }^{2}$ Health, Environment and Development Foundation, Lagos, Nigeria \\ Email: `bmafolabi@gmail.com, „heendef05@gmail.com
}

How to cite this paper: Ajayi, A.B., Afolabi, B.M., Ajayi, V.D., Oyetunji, I.O., Atiba, A., Saanu, S., Adeoye, A.T., Ehichioya, J. and Ayelehin, I.I. (2020) Frequency of Monthly Ejaculation at Sexual Intercourse, DNA Fragmentation Index and Fertilization Rate among Sperm Donors and Fertility-Challenged Men in Sub-Saharan Africa: Paper 2. Open Journal of Urology, 10, 60-78.

https://doi.org/10.4236/oju.2020.103008

Received: December 18, 2019

Accepted: February 25, 2020

Published: February 28, 2020

Copyright $\odot 2020$ by author(s) and Scientific Research Publishing Inc. This work is licensed under the Creative Commons Attribution International License (CC BY 4.0).

http://creativecommons.org/licenses/by/4.0/ (c) (i) Open Access

\begin{abstract}
Introduction: Heterogenous sexual intercourse often produces a powerful orgasm that stimulates the pituitary function. Studies have suggested ejaculation frequency based on age. Materials and Methods: Semi-structured questionnaires were used to collect information from subjects. Semen samples were collected from sperm donors and sub-fertile men who presented for infertility challenges. Processing and analysis of semen samples were done according to World Health Organization (WHO) guidelines. Sperm deoxyribonucleic acid (DNA) fragmentation was evaluated using the Halosperm kit. Results: Among sperm donors, those aged $<40$ years were twice as likely to have very low $(1-5)$ frequency of monthly ejaculations at sexual intercourse (MESI) compared to those aged $\geq 40$ years $\left(\chi^{2}=0.09, \mathrm{P}\right.$-value $=0.81, \mathrm{OR}=$ 3.2 , 95\% CI: $0.23,45.19)$ while among sub-fertile men those aged $\geq 40$ years were approximately 2.3 times more likely to have very low frequency of MESI compared to aged $<40$ years $\left(\chi^{2}=2.11, \mathrm{P}\right.$-value $=0.51, \mathrm{OR}=2.27,95 \% \mathrm{CI}$ : $0.74,9.92)$. The frequency of all categories of MESI was highest among sub-fertile men aged $<40$ and those aged $\geq 40$ years who never smoked or who never used herbal teas. There was no consistency in the frequency of MESI among those who never took alcohol in both age groups. Overall, systolic blood pressure ( $\mathrm{mmHg}$ ) declined gradually as frequency of MESI increased though the observed decline was not statistically significant (F-test $=0.19, \mathrm{P}$-value $=$ $0.90)$. Sub-fertile men aged $\geq 40$ with systolic hypertension $(\geq 140 \mathrm{mmHg})$
\end{abstract}


were approximately $21 / 2$ times more likely to have a low $(6-10)$ frequency of MESI compared to those aged $<40$ years $\left(\chi^{2}=0.03\right.$, P-value $=0.57, \mathrm{OR}=$ 2.42, 95\% CI: 0.41, 14.46). Sub-fertile men aged $\geq 40$ with diastolic hypertension $(\geq 90 \mathrm{mmHg})$ were approximately 6 times more likely to have a low (610) frequency of MESI compared to those aged $<40$ years $\left(\chi^{2}=1.97\right.$, P-value $=$ $0.16, \mathrm{OR}=6.22,95 \% \mathrm{CI}: 0.69,55.77)$. Overall mean fertilization rate was significantly higher ( $\mathrm{t}$-test $=2.44$, P-value $=0.01$ ) among sub-fertile men aged $<40$ years $(85.3 \pm 13.2)$ than among those aged $\geq 40$ years $(9.3 \pm 24.8)$. Mean fertilization rate among those with DNA fragmentation index $<25 \%$ was significantly higher ( $\mathrm{t}$-test $=2.14$, P-value $=0.03$ ) among those aged $<40$ years $(88.6 \pm 12.3)$ than among those aged $\geq 40$ years $(67.1 \pm 24.0)$. Conclusion: Cigarette smoking, more than alcohol consumption, appears to be a major factor that significantly affects the frequency of MESI among sub-fertile men in all age groups. Frequency of MESI negatively but insignificantly correlated with systolic blood pressure.

\section{Keywords}

Monthly Ejaculation at Sexual Intercourse, Systolic and Diastolic Blood Pressures, DNA Fragmentation Index, Fertilization Rates, Social Habits, Sub-Fertile Males, Sub-Sahara Black Africans

\section{Introduction}

Human spermatozoa are produced in the seminiferous tubules and are stored in the epididymis where they undergo a series of physiological and biochemical changes, allowing them to mature and acquire fertilizing potential before release [1]. Globally, frequency of male ejaculation at sexual intercourse, has been associated with risk of prostate cancer, though a recent Harvard Ejaculation Study (HES) found no evidence that frequent ejaculations markedly increased risk of prostate cancer [2]. From another perspective, Courtois et al. reported systematic variations in blood pressure at drug-induced ejaculation among men with spinal cord injury, indicating a possible relationship between ejaculation and blood pressure with or without medication [3]. An anecdotal report by European researchers indicates that as frequency of sexual intercourse, thus ejaculation, increases, blood pressure decreases [4]. It has also been suggested that frequent sex is good for the health of men [5] [6] but there is not enough data to prove this point. It's not certain if good health makes one more willing to have sexual intercourse or if sexual intercourse has a positive impact on health. It is assumed that health benefits of sexual intercourse are generally thought to accrue to people in loving, monogamous relationships. Risky sexual intercourse with lots of partners may do more harm than good [7]. Release of sperm cells at ejaculation often leads to pregnancy in the female, though frequency of ejaculation may not necessarily be related to chances of becoming pregnant. Most data on ejacu- 
lation at sexual intercourse derive from studies in Europe and America. There is a large lacuna on frequency of MESI among sperm donors and among indigenous sub-fertile Black men in sub-Sahara Africa. The objectives of this study were to: 1) report frequency of MESI among sperm donors and among sub-fertile men; 2) document factors that significantly affect the frequency of monthly ejaculations at sexual intercourse in sub-fertile Black African men; 3) report on effect of MESI on health of sub-fertile men, including relationship between monthly ejaculations and systolic and diastolic blood pressures.

\section{Materials and Methods}

The second part of this paper involves 1) factors that affect the frequency of MESI significantly, 2) the effect of high, medium or low frequency of monthly ejaculation at sexual intercourse on health of subjects of study, and 3) fertilization rate among sperm donors and also among sub-fertile men who had in-vitro-fertilization (IVF) relative to DNA fragmentation and MESI.

Just as in the first part, this second part of the study utilized the same semi-structured questionnaire designed to collect socio-demographic data; history, type and duration of infertility, miscarriage in partners and if subject had ever fathered a child or not. All the subjects who came for sperm donation, who consulted for male infertility within the study period and who gave informed consent were included in the study except those who could not produce semen, those who declined consent and those whose information was inaccurate. The investigations here revolved around frequency of monthly ejaculation at sexual intercourse (MESI), systolic and diastolic blood pressures, history of hypertension and of diabetes, social habits such as cigarette smoking and alcohol consumption as well as use of medicinal herbs (agbo). Materials and methods for the second part of the study was essentially the same as in the first part of the study. Briefly, each patient, whether a sperm donor or a patient consulting for male factor infertility submitted semen samples-collected by masturbation-which were processed strictly in accordance with WHO specification as described in our earlier paper [8]. Semen samples were collected after a duration of 2 - 7 days abstinence of sexual intercourse and transported almost immediately to the laboratory for analysis. Each patient was counselled on: 1) the need for accuracy in the collection of semen; 2) the kits (wide-mouth measuring cylinder) to be used for the collection; and 3) the need to report any loss of semen during collection. Conventional seminal fluid analysis (SFA) was performed according to WHO guidelines [9] for semen volume, total sperm count, motility, and morphology. The determination of human sperm DNA fragmentation index (DFI \%) has been rendered in our earlier paper [10]. Included in this study were all patients who presented for sperm donation, who consulted for male infertility management within the study period and those who gave informed consent. All consenting men who presented for fertility assessment; those who were currently or within two weeks prior to analysis, not on any medication, particularly 
anabolic steroids, antibiotics and antimalarials, or any medication that would have interfered with spermatogenesis were included into the study. Excluded from the study were those who could not produce semen, those who declined consent for various reasons such as fasting and whose information was inaccurate.

\section{Statistical Analysis}

The statistical analysis used in part 1 one of this paper was also applicable to part 2. In brief, age was stratified into $<40$ and $\geq 40$ years old, Body Mass Index (BMI) into underweight (BMI < 18.5), normal weight (BMI 18.5 - 24.9), overweight (BMI 25.0 - 29.9) and obese (BMI $\geq 30$ ), though there was no underweight subject. Frequency of monthly ejaculation at sexual intercourse (MESI) was classified as 1 for a frequency of 1 - 5, 2 for 6 - 10, 3 for $11-15$ and 4 for $16-20$. Sperm DNA fragmentation index (SDFI) was categorized as $<25 \%$ or good SDFI and $\geq 25 \%$ as bad SDFI. Statistical analysis was performed using STATA 13 for Windows (Stata Corps, College Station, Texas 77845, USA). All variables were initially tested to determine variance homogeneity and data normality, and heteroscedastic data were transformed. Groups were compared using one-way ANOVA. Analyses carried out included frequency and percentage of proportions, appropriate bivariate (cross-tabulation) and multivariate regression analysis. Statistical variances between means were decided by Student's t-test when comparing 2 groups and by Kruskal-Wallis when comparing more than 2 groups. Outcomes were given as mean ( \pm standard deviation $[s d]$ ). The significance of differences between two or more than two proportions was determined using Chi-square $\left(\chi^{2}\right)$ test. Odds ratio was determined at 95\% Confidence Interval. Data were presented as figures, tables and graphs. Association between sperm DNA fragmentation index and continuous variables such as MESI was assessed using Linear Regression Analysis. Level of significance was set at $\mathrm{P}<0.05$.

Ethical approval. This descriptive study conducted in 2018 was approved by the Nigerian Institute for Medical Research Institutional Review Board (NIMR $\mathrm{IRB} / 18 / 007)$.

\section{Results}

Factors that significantly affect frequency of ejaculation at sexual intercourse (MESI) among sperm donors (Table 1, Figure 1).

Of the 114 subjects of this study, sperm donors accounted for only 19 (16.6\%) made up of $16(84.2 \%)$ that were aged $<40$ years and only $3(15.8 \%)$ aged 40 years and above (Table 1). The socio-demographic profile of study participants has already been reported earlier [11]. Sperm donors aged $<40$ years were twice as likely to have a very low ( 1 - 5) frequency of MESI compared to their older counterparts $\left(\chi^{2}=0.00, \mathrm{P}\right.$-value $\left.=1.00, \mathrm{OR}=2.0,95 \% \mathrm{CI}: 0.15,26.74\right)$ but were not as likely to have a high $(11-15)$ frequency of MESI as those aged $\geq 40$ years $\left(\chi^{2}=0.27, \mathrm{P}\right.$-value $\left.=0.61, \mathrm{OR}=0.23,95 \% \mathrm{CI}: 0.02,3.13\right)$. Furthermore, DNA 
Table 1. Factors that significantly affect the frequency of monthly ejaculation significantly among sperm donors in the study.

\begin{tabular}{|c|c|c|c|c|c|c|}
\hline \multirow{3}{*}{\multicolumn{2}{|c|}{ Variables }} & \multirow{3}{*}{ Sub-variables } & \multicolumn{4}{|c|}{ All } \\
\hline & & & \multicolumn{4}{|c|}{ Frequency of MESI } \\
\hline & & & $\begin{array}{c}1-5 \\
(\mathrm{n}=9,47.4 \%)\end{array}$ & $\begin{array}{c}6-10 \\
(\mathrm{n}=1,5.3 \%)\end{array}$ & $\begin{array}{c}11-15 \\
(\mathrm{n}=7,36.8 \%)\end{array}$ & $\begin{array}{c}16-20 \\
(\mathrm{n}=2,10.5 \%)\end{array}$ \\
\hline \multirow{4}{*}{\multicolumn{2}{|c|}{ Age (years) }} & $<40$ & $8(88.9)^{*}$ & $1(100.0)$ & $5(71.4)$ & $2(100.0)$ \\
\hline & & $\geq 40$ & $1(11.1)$ & $0(0.0)$ & $2(28.6)$ & $0(0.0)$ \\
\hline & & $\chi^{2}(\mathrm{P}$-value $)$ & $0.0(1.00)$ & $0.0(1.00)$ & $0.27(0.61)$ & $0.0(1.00)$ \\
\hline & & OR (95\% CI) & $2.00(0.15,26.74)$ & undefined & $0.23(0.02,3.13)$ & undefined \\
\hline \multirow{3}{*}{\multicolumn{2}{|c|}{ BMI $\left(\mathrm{kg} / \mathrm{m}^{2}\right)$}} & $18.5-24.9$ & $4(44.5)$ & $0(0.0)$ & $4(57.1)$ & $2(100.0)$ \\
\hline & & $25.0-29.9$ & $3(33.3)$ & $1(100.0)$ & $1(14.3)$ & $0(0.0)$ \\
\hline & & $\geq 30$ & $2(22.2)$ & $0(0.0)$ & $2(28.6)$ & $0(0.0)$ \\
\hline \multirow{4}{*}{\multicolumn{2}{|c|}{ DFI (\%) }} & $<25$ & $5(55.5)$ & $0(0.0)$ & $0(0.0)$ & $0(0.0)$ \\
\hline & & $\geq 25$ & $4(44.5)$ & $1(100.0)$ & $7(100.0)$ & $2(100.0)$ \\
\hline & & $\chi^{2}(\mathrm{P}$-value $)$ & $4.95(0.03)$ & $0.0(1.00)$ & $2.10(0.15)$ & $0 . .00(0.96)$ \\
\hline & & OR (95\% CI) & undefined & undefined & undefined & undefined \\
\hline \multirow{8}{*}{$\begin{array}{l}\text { Social } \\
\text { habits }\end{array}$} & \multirow{4}{*}{ Smoking } & Never & $9(100.0)$ & $0(0.0)$ & $5(71.4)$ & $2(100.0)$ \\
\hline & & Ever & $0(0.0)$ & $1(100.0)$ & $2(28.6)$ & $0(0.0)$ \\
\hline & & $\chi^{2}(\mathrm{P}$-value $)$ & $1.35(0.25)$ & $0.93(0.33)$ & $0.27(0.61)$ & $0.0(1.00)$ \\
\hline & & OR (95\% CI) & undefined & undefined & $0.23(0.02,3.13)$ & undefined \\
\hline & \multirow{4}{*}{ Alcohol intake } & Never & $6(66.7)$ & $0(0.0)$ & $2(28.6)$ & $0(0.0)$ \\
\hline & & Ever & $3(33.3)$ & $1(100.0)$ & $5(71.4)$ & $2(100.0)$ \\
\hline & & $\chi^{2}(\mathrm{P}$-value $)$ & $2.53(0.11)$ & $0.0(1.00)$ & $0.19(0.67)$ & $0.27(0.60)$ \\
\hline & & OR (95\% CI) & $8.00(1.00,63.97)$ & undefined & $0.40(0.05,2.93)$ & undefined \\
\hline \multirow{4}{*}{\multicolumn{2}{|c|}{ Use herbal tea }} & Never & $6(66.7)$ & $1(100.0)$ & $5(71.4)$ & $1(50.0)$ \\
\hline & & Ever & $3(33.3)$ & $0(0.0)$ & $2(28.6)$ & $1(50.0)$ \\
\hline & & $\chi^{2}$ (P-value) & $0.0(1.00)$ & $0.0(1.00)$ & $0.0(1.00)$ & $0.0(1.00)$ \\
\hline & & OR (95\% CI) & $0.86(0.12,5.94)$ & undefined & $1.25(0.16,9.54)$ & $0.42(0.02,8.05)$ \\
\hline
\end{tabular}

Note: Fisher's exact test was used in all statistical calculations. ${ }^{*}=(\%)$.

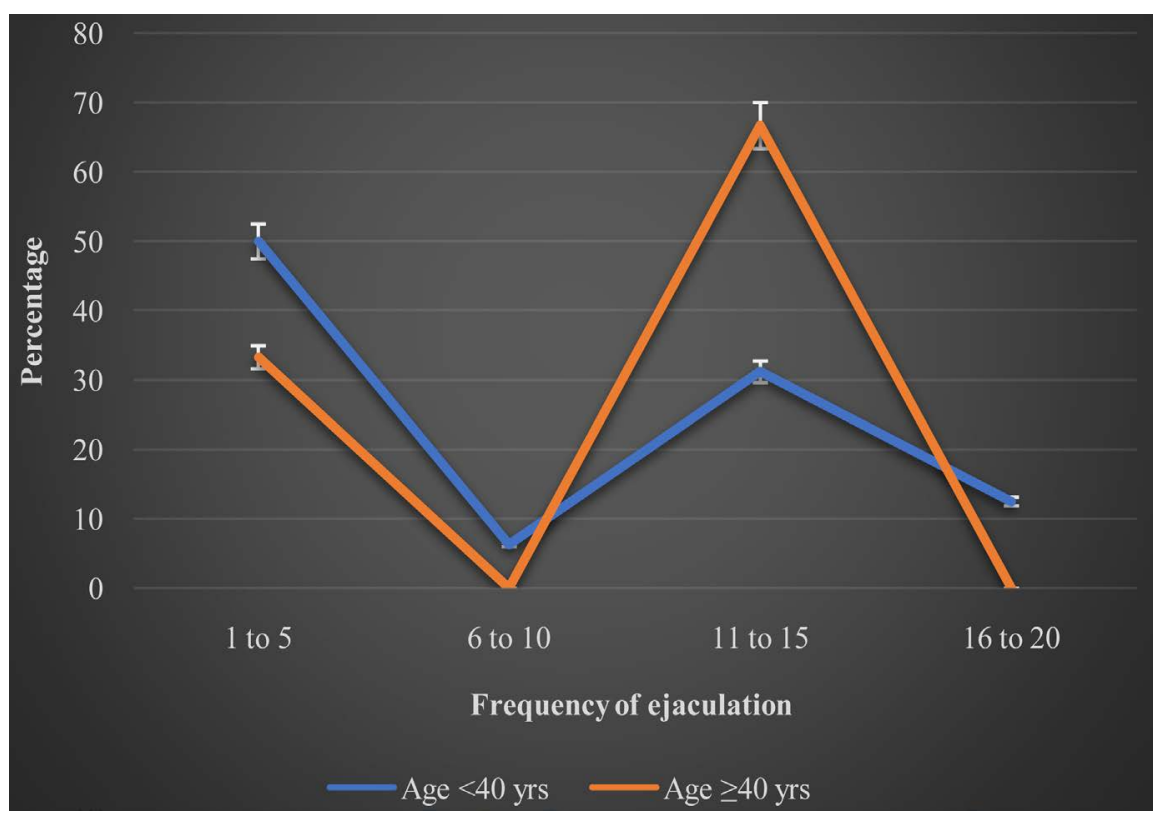

Figure 1. Comparative analysis of frequency of monthly ejaculation at sexual intercourse relative to age groups of sperm donors. 
fragmentation index appeared to be an intrinsic factor that significantly affected MESI among sperm donors as a significant proportion of those with very low $(1-5)$ frequency of MESI $\left(\chi^{2}=4.95\right.$, P-value $\left.=0.03\right)$ had DFI $<25 \%$ compared to those with DFI $\geq 25 \%$. Most (50.0\%) sperm donors $<40$ years reported low (1 5) frequency of MESI and only $12.5 \%$ of them reported very high frequency (16 20) while those aged 40 years and above mostly reported lower frequencies of MESI except frequency of $11-15$.

Factors that significantly affect frequency of ejaculation at sexual intercourse (MESI) among sub-fertile men (Table 2, Figure 2).

Our results suggested that, overall, age was one of the factors that significantly affected the frequency of MESI among the sub-fertile subjects of this study. Firstly, among those who reported low frequency ( 1 - 5) of MESI, approximately $74 \%$ (14/19) were aged 40 and above and only $26 \%(5 / 19)$ were younger subjects. On the contrary, a significant proportion $\left(\chi^{2}=4.76, \mathrm{P}\right.$-value $\left.=0.03\right)$ of those aged $<40$ years $(19 / 34,55.9 \%)$ had high frequency of ejaculation at sexual intercourse than those aged $\geq 40$ years. In the final analysis, mean overall frequency of MESI among those aged $<40$ years $(10.8 \pm 3.8)$ was significantly higher $(\mathrm{t}$-test $=$ 2.20 , P-value $=0.02)$ than that among older men aged $\geq 40$ years. Though influenced by age, another factor that appeared to significantly affect the frequency of MESI was DNA fragmentation index, as a higher proportion of those $<40$ years with DFI $<25 \%$ reported very high frequency $(16-20)$ of MESI while a marginally significant proportion of older men $\left(\chi^{2}=3.67, \mathrm{P}\right.$-value $\left.=0.05\right)$ recorded low frequency (6 - 10) of MESI.

Surprisingly, among those who reported a low (6 - 10) frequency of MESI the overall proportion of those who had ever fathered a child (53.6\%) was significantly higher $\left(\chi^{2}=7.68, \mathrm{P}\right.$-value $\left.=0.006\right)$ compared to those who reported other frequencies of MESI indicating that those who had ever fathered a child were more likely to be having lower frequency of MESI than those who had never fathered a child or that those who had never fathered a child would be having a higher frequency of MESI than those who had ever fathered a child. However, although the mean frequency of MESI among those who had never fathered a child $(10.1 \pm 4.5)$ was higher than that of those who had ever fathered a child $(8.8 \pm 4.0)$, the difference was not statistically significant. Approximately $50 \%$ of sub-fertile men aged 40 years or more reported lower frequencies of MESI except $11-15 /$ month while only $26.8 \%$ of those aged $<40$ years reported this category of MESI.

Effect of frequency of monthly ejaculation at sexual intercourse on health of sub-fertile male (Table 3 ).

Firstly, 31 (32.6\%) sub-fertile study subjects had systolic hypertension including $7(36.8 \%)$ of the 19 who reported very low (1 - 5) frequency of MESI, 9 $(31.0 \%)$ of those who reported low (6 - 10) frequency, 12 (35.3\%) of those who informed high $(10-15)$ frequency and 3 of the $13(23.1 \%)$ that stated very high frequency $(16-20)$ of MESI $\left(\chi^{2}=2.31\right.$, P-value $\left.=0.51\right)$. A relatively high proportion 
Table 2. Factors that significantly affected the frequency of monthly ejaculation among sub-fertile men in the study.

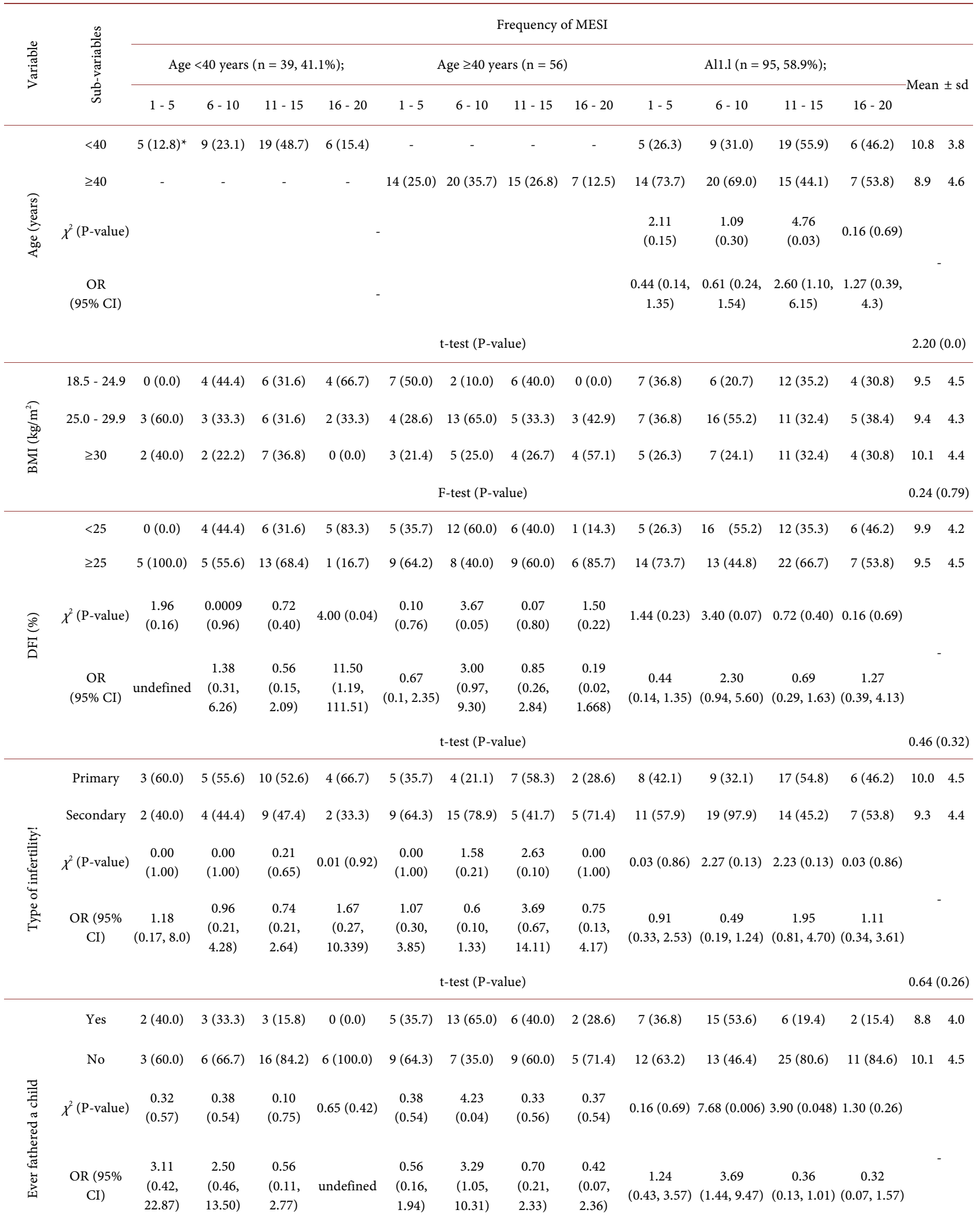




\section{Continued}

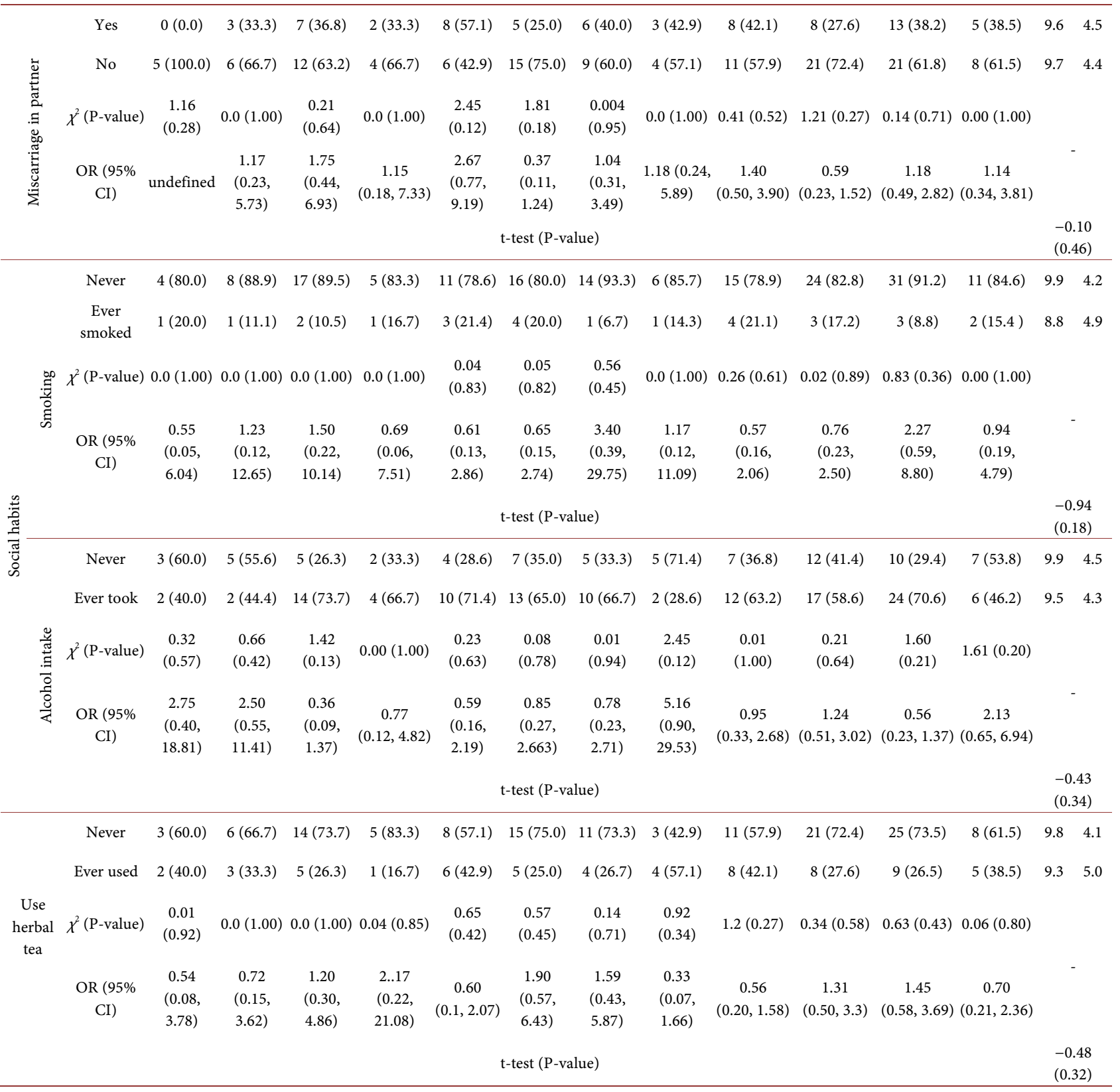

* $=(\%) ; ! 4$ people without history of infertility were excluded in the analysis.

of men with systolic hypertension had high frequency of MESI. There was no significant difference in the overall systolic blood pressure $(\mathrm{mmHg})$ of sub-fertile men in any age group relative to frequency of monthly ejaculation at sexual intercourse. It was however observed that, overall, systolic blood pressure $(\mathrm{mmHg})$ seemed to gradually decline from 133.4 through $130.0,129.7$ and finally 128.1 among the subjects reporting very low (1 - 5), low (6 - 10), high (11 - 15) and very high (16 - 20) frequency of MESI. Results from this study however observed a significantly higher $(\mathrm{t}=4.40, \mathrm{P}$-value $=0.01)$ mean diastolic blood pressure (103 $\mathrm{mmHg}$ ) among hypertensive sub-fertile men $\geq 40$ years who reported high (11 - 15) frequency of MESI than other categories of MESI. 
Table 3. Effect of frequency of monthly ejaculation at sexual intercourse on health of sub-fertile male.

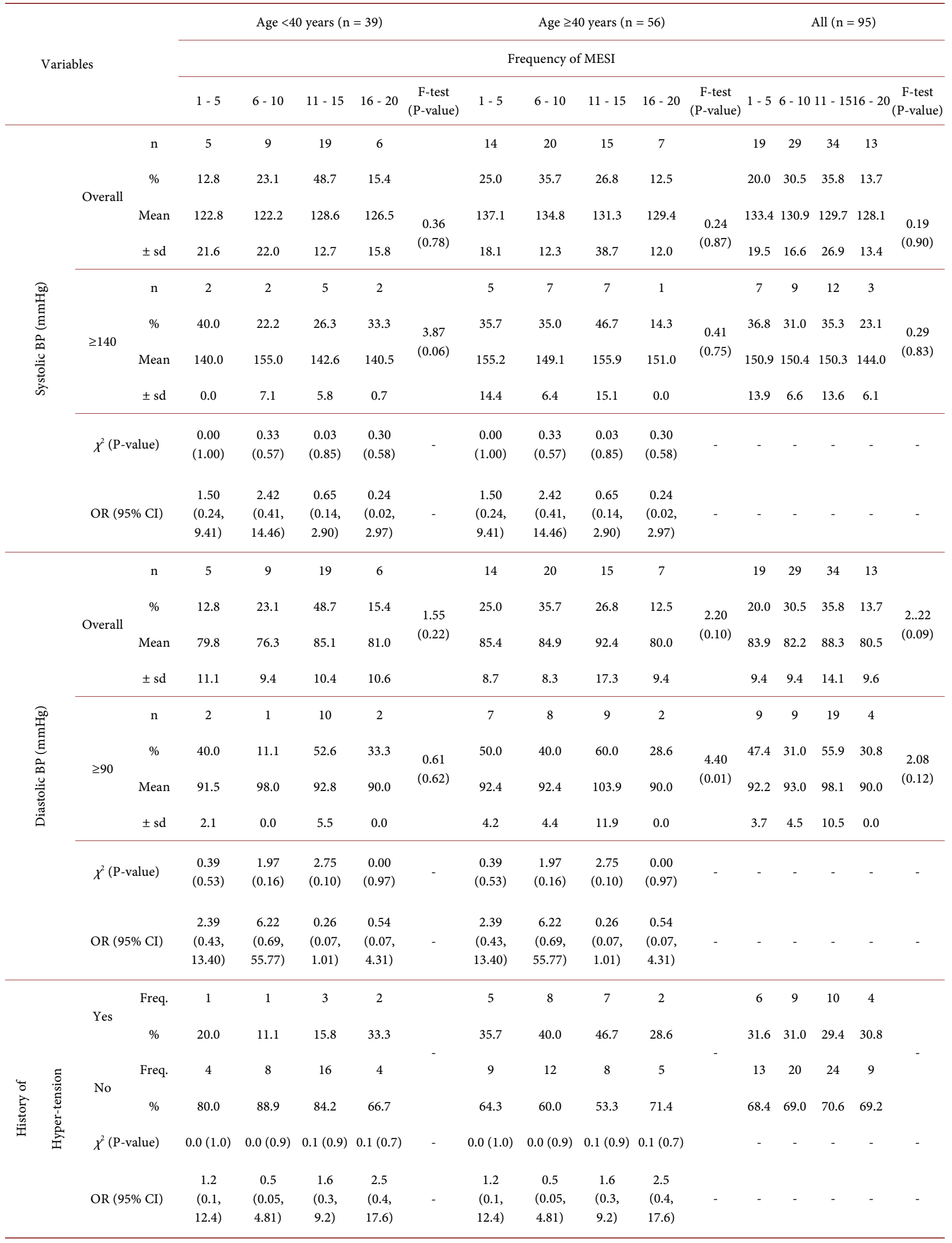




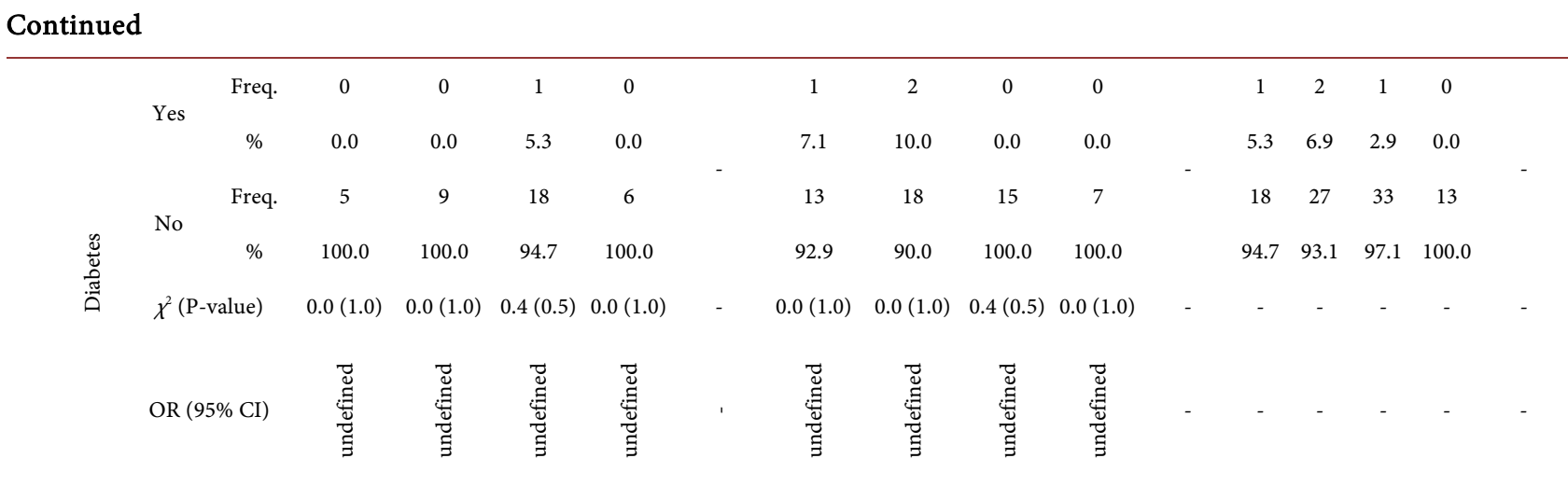

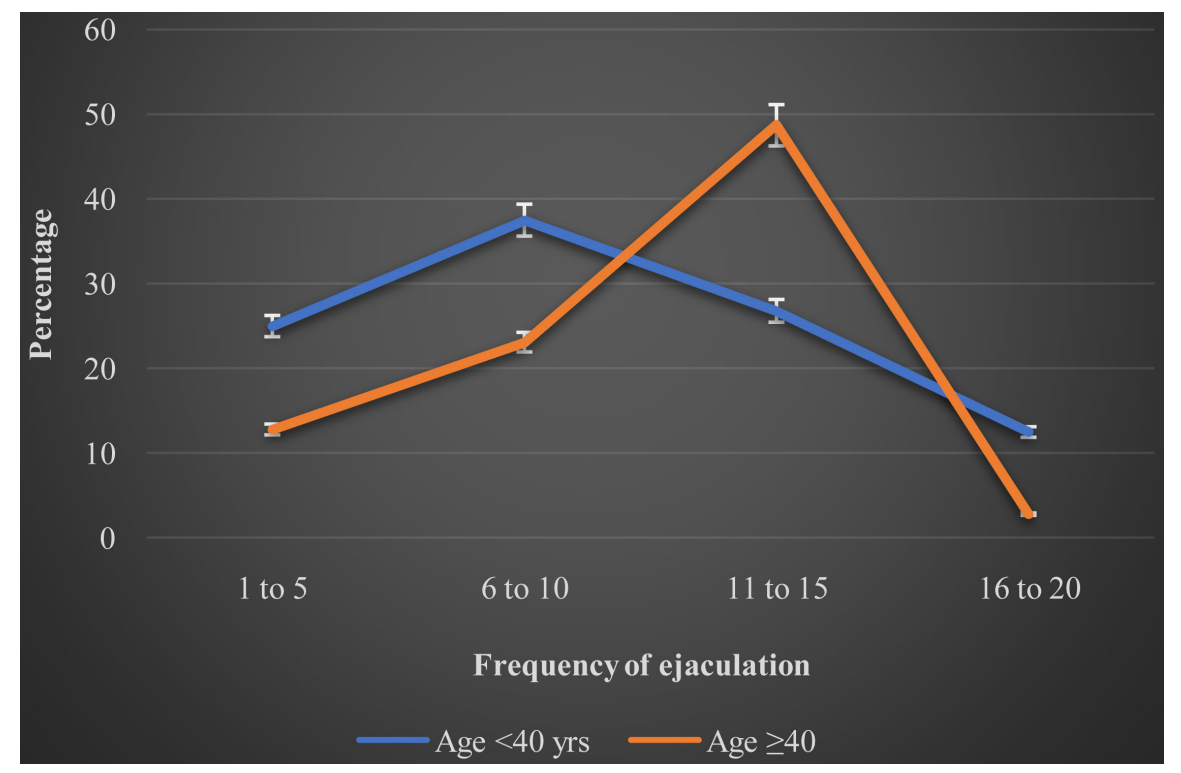

Figure 2. Comparative analysis of frequency of monthly ejaculation at sexxual intercourse relative to age groups of sub-fertile men in the study.

\section{Mean frequency of MESI among subjects with and without systolic and} diastolic hypertension relative to age, BMI and social habits of sub-fertile subjects (Table 4, Figure 3).

Diastolic hypertension was clinically observed in $41(43.2 \%)$ of the study subjects including 9 (22.0\%) of the 19 with very low frequency of MESI, another 9 (31.0\%) of the 29 with low, 19 (55.9\%) of the 34 with high and 4 (30.8\%) of the 13 with very high frequency of MESI $\left(\chi^{2}=5.73\right.$, P-value $\left.=0.13\right)$. Thus, a relatively high proportion of sub-fertile men with diastolic hypertension have high frequency of monthly ejaculation. The findings in Table 3 prompted a further probe into whether there was a relationship between frequency of MESI and those with or without systolic or diastolic hypertension. The mean frequency of MESI $(10.9 \pm 3.8)$ among sub-fertile men aged $<40$ years with systolic blood pressure < $140 \mathrm{mmHg}$ was significantly higher $(\mathrm{t}$-test $=1.67, \mathrm{P}$-value $=0.049)$ than that among men aged $\geq 40$ years $(9.1 \pm 4.8)$ while the mean frequency of MESI (11.4 \pm 4.1 ) among those aged $<40$ years with diastolic hypertension was significantly 
Table 4. Mean frequency of MESI among subjects with and without systolic and diastolic hypertension relative to age, BMI and social habits of sub-fertile subjects.

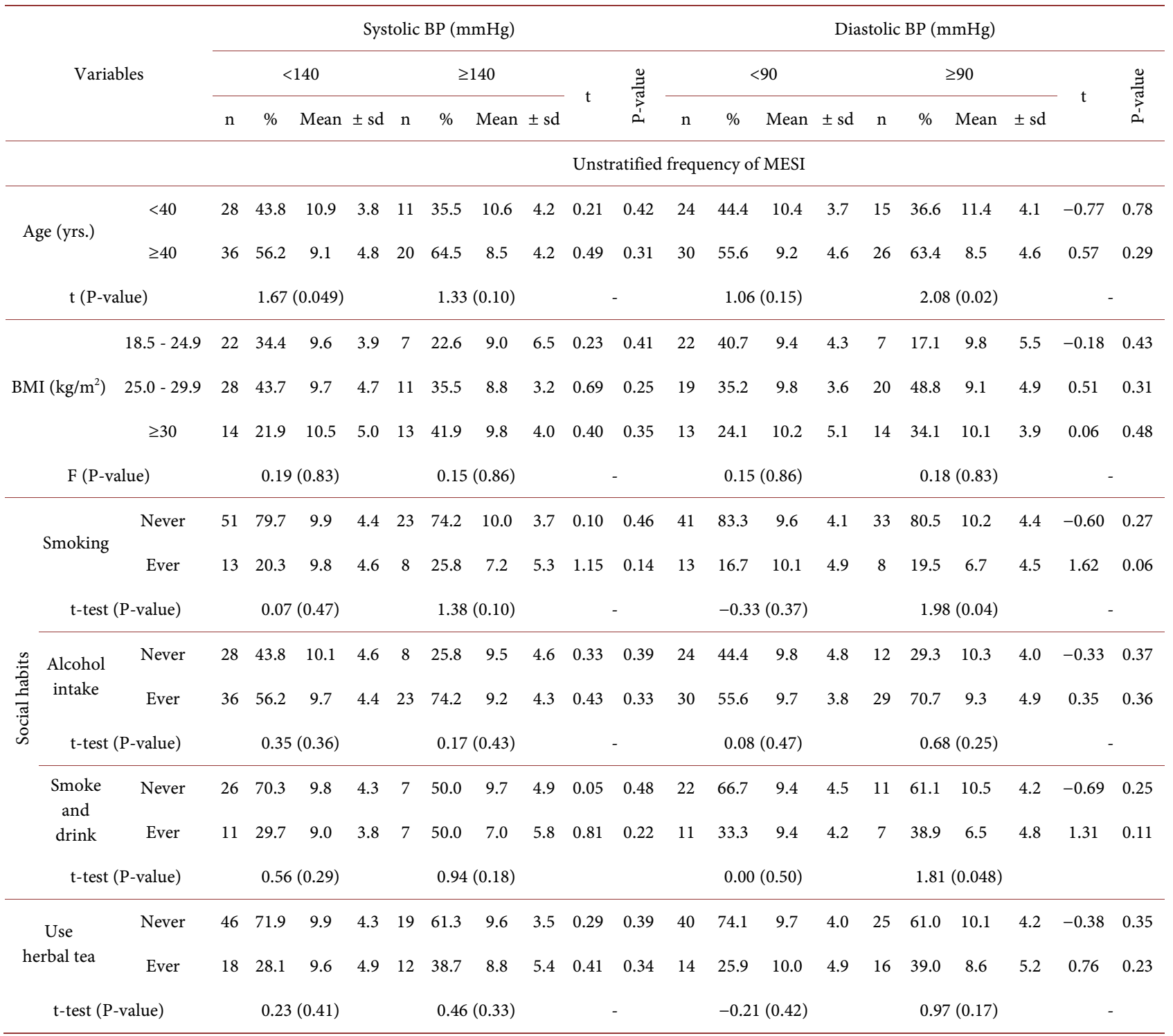

higher $(\mathrm{t}$-test $=2.08, \mathrm{P}$-value $=0.02)$ compared to the mean frequency of MESI among those aged $\geq 40$ years. Furthermore, this study observed a significantly higher frequency $(t=1.98, \mathrm{P}$-value $=0.04)$ of MESI among those who never smoked but with diastolic hypertension $(10.2 \pm 4.4)$ compared to those who ever smoked but still with diastolic hypertension ( $6.7 \pm 4.5)$. Also, there was a significant difference $(\mathrm{t}=1.81, \mathrm{P}$-value $=0.048)$ in the frequency of MESI among those who never smoked and never took alcohol $(10.5 \pm 4.2)$ and those who ever smoked and ever took alcohol (6.5 \pm 4.8$)$. Of the 95 subjects 6 (6.3\%) presented with systolic but not diastolic hypertension, $16(16.8 \%)$ presented with diastolic but not systolic hypertension and 25 (26.3\%) presented with both systolic and diastolic hypertension with no significance difference in the mean frequency of their MESI. The mean frequency of ejaculations among those with systolic hypertension alone 


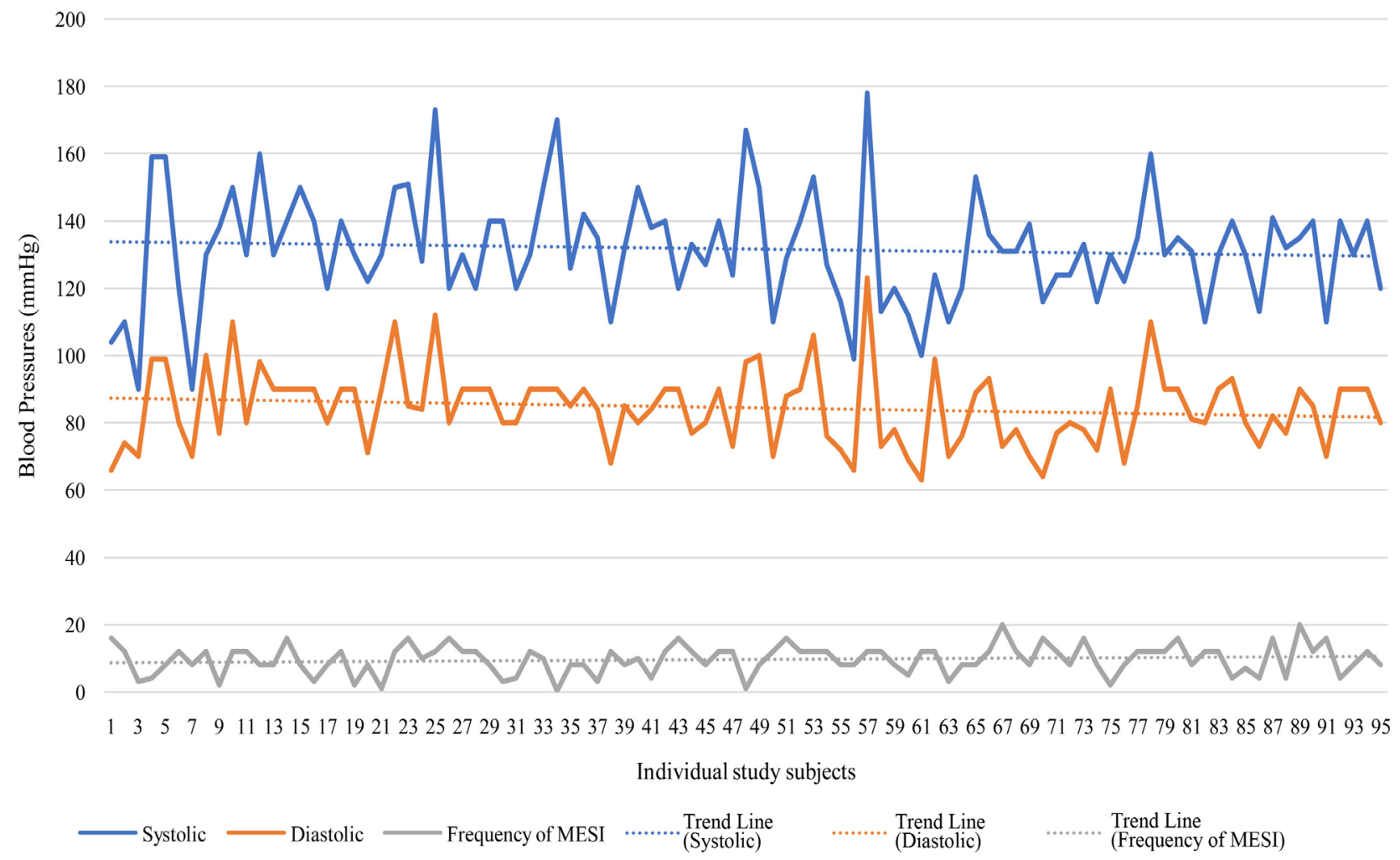

Figure 3. Systolic and diastolic Blood Pressures ( $\mathrm{mmHg}$ ) and frequency of MESI for each sub-fertile stuy subject. Of the 95 subjects $6(6.3 \%)$ presented with systolic but not diastolic hypertension, 16 (16.8\%) presented with diastolic but not systolic hypertension and $25(26.3 \%)$ presented with both systolic and diastolic hypertension with no significance difference in the mean frequency of their MESI.

$(10.8 \pm 5.0)$ was not significantly different from that among those with diastolic hypertension alone $(10.6 \pm 5.3)$ or those with both systolic and diastolic hypertension $(8.9 \pm 4.4)$.

Fertilization rate among sub-fertile men who had IVF relative to DNA fragmentation (Table 5).

The next analysis was the fertilization rate of men who proceeded to have IVF, considering their DNA fragmentation level. Overall mean fertilization rate was $77.8 \%$ with a substantial variation ( $\mathrm{t}$-test $=2.44, \mathrm{P}$-value $=0.01$ ) between the mean fertilization rate of those aged $<40$ years $(85.3 \pm 13.2)$ and those aged $\geq 40$ years $(69.3 \pm 24.8)$. This difference appeared to be driven by higher mean fertilization rate among: 1) sub-fertile men aged $<40$ year with DNA fragmentation index of $<25 \%(88.6 \pm 12.3)$; and that among 2$)$ sub-fertile men aged $\geq 40$ years with DNA fragmentation index on $<25 \%(67.1 \pm 24.0)$. There was a marginally significant mean fertilization rate among those with DNA fragmentation index $\geq 25 \%$ relative to frequency of MESI (F-test $=3.00$, P-value $=0.05$ ), though this appeared to be influenced by the lone subject who had IVF in the MESI category of 16 - 20. There was a marginally significant variation ( $\mathrm{t}$-test $=0.05, \mathrm{P}$-value $=$ 0.05 ) in the overall mean fertilization rate among those who never smoked $(77.8 \pm 21.0)$ compared to those who ever smoked $(77.1 \pm 25.2)$. 
Table 5. Fertilization rate among sub-fertile men who had IVF relative to DNA fragmentation.

\begin{tabular}{|c|c|c|c|c|c|c|c|c|c|c|c|c|c|c|c|c|c|c|c|}
\hline \multirow{4}{*}{ Variable } & \multirow{4}{*}{ Item } & \multicolumn{6}{|c|}{ DNA fragmentation index $<25 \%$} & \multicolumn{6}{|c|}{ DNA fragmentation index $\geq 25 \%$} & \multirow{4}{*}{ - $\mathrm{t}$-test } & \multirow{4}{*}{ P-value } & \multirow{2}{*}{\multicolumn{4}{|c|}{$\begin{array}{c}\text { All } \\
\text { Fertilization rate }\end{array}$}} \\
\hline & & \multirow[t]{3}{*}{ Freq. } & \multirow[t]{3}{*}{$\%$} & \multirow{2}{*}{\multicolumn{4}{|c|}{$\begin{array}{c}\text { Fertilization rate } \\
\text { Had IVF }\end{array}$}} & \multirow{3}{*}{ Freq. } & \multirow{3}{*}{$\%$} & \multirow{2}{*}{\multicolumn{4}{|c|}{ Fertilization rate }} & & & & & & \\
\hline & & & & & & & & & & & & & & & & & $\mathrm{Had}$ & d IVF & \\
\hline & & & & Freq. & $\%$ & Mean & $\pm \mathrm{sd}$ & & & Freq. & $\%$ & Mean & $\pm \mathrm{sd}$ & & & Freq. & $\%$ & Mean & $\pm \mathrm{sd}$ \\
\hline \multicolumn{2}{|l|}{ All } & 39 & 41.0 & 17 & 43.6 & 77.2 & 21.8 & 56 & 59.0 & 21 & 37.5 & 78.2 & 20.7 & -0.14 & 0.44 & 38 & 40.0 & 77.8 & 20.9 \\
\hline \multirow{3}{*}{ Age (yrs.) } & $<40$ & 15 & 38.5 & 8 & 47.1 & 88.6 & 12.3 & 24 & 42.9 & 12 & 57.1 & 83.2 & 13.9 & 0.91 & 0.19 & 20 & 52.6 & 85.3 & 13.2 \\
\hline & $\geq 40$ & 24 & 61.5 & 9 & 52.9 & 67.1 & 24.0 & 32 & 57.1 & 9 & 42.9 & 71.5 & 26.9 & -0.37 & 0.36 & 18 & 47.4 & 69.3 & 24.8 \\
\hline & \multicolumn{3}{|c|}{ t-test (P-value) } & \multicolumn{4}{|c|}{$2.14(0.03)$} & & & \multicolumn{4}{|c|}{$1.19(0.13)$} & \multicolumn{2}{|r|}{-} & \multicolumn{4}{|c|}{$2.44(0.01)$} \\
\hline \multirow{4}{*}{$\mathrm{BMI}\left(\mathrm{kg} / \mathrm{m}^{2}\right)$} & $\begin{array}{c}18.5- \\
24.9\end{array}$ & 15 & 38.5 & 7 & 41.2 & 75.0 & 26.8 & 14 & 25.0 & 7 & 33.3 & 85.5 & 14.2 & -0.92 & 0.19 & 14 & 36.8 & 80.2 & 21.3 \\
\hline & $\begin{array}{c}25.0- \\
29.9\end{array}$ & 16 & 41.0 & 7 & 41.2 & 77.8 & 22.9 & 23 & 41.1 & 8 & 38.1 & 74.5 & 17.7 & 0.30 & 0.38 & 15 & 39.5 & 76.0 & 19.6 \\
\hline & $\geq 30$ & 8 & 20.5 & 3 & 17.6 & 81.2 & 6.3 & 19 & 33.9 & 6 & 28.6 & 74.5 & 30.4 & 0.52 & 0.31 & 9 & 23.7 & 76.8 & 24.5 \\
\hline & \multicolumn{3}{|c|}{ F-test (P-value) } & \multicolumn{4}{|c|}{$0.08(0.92)$} & \multicolumn{2}{|c|}{ - } & \multicolumn{4}{|c|}{$0.63(0.55)$} & & - & & 0.15 & $(0.86)$ & \\
\hline & $1-5$ & 5 & 12.8 & 1 & 5.9 & 33.3 & 0.0 & 14 & 25.0 & 7 & 33.3 & 80.0 & 20.6 & - & - & 8 & 21.1 & 74.2 & 25.2 \\
\hline & $6-10$ & 16 & 41.0 & 5 & 29.4 & 73.1 & 22.5 & 13 & 232 & 6 & 28.6 & 80.9 & 19.3 & -0.61 & 0.28 & 11 & 28.9 & 77.3 & 20.1 \\
\hline ejaculation & $11-15$ & 12 & $30 . .8$ & 9 & 52.9 & 79.4 & 17.7 & 22 & 39.3 & 7 & 33.3 & 81.6 & 14.2 & -0.28 & 0.39 & 16 & 42.1 & 80.4 & 15.8 \\
\hline & $16-20$ & 6 & 15.4 & 2 & 11.8 & 100.0 & 0.0 & 7 & 12.5 & 1 & 4.8 & 25.0 & 0.0 & - & - & 3 & 7.9 & 75.0 & 43.3 \\
\hline & F-tes & (P-val & & & 2.97 & $(0.07)$ & & & & & 3.00 & $(0.05)$ & & & - & & 0.17 & $(0.92)$ & \\
\hline & Never & 34 & 87.2 & 14 & 88.2 & 77.3 & 22.1 & 47 & 84.0 & 21 & 100.0 & 78.2 & 20.7 & -0.10 & 0.46 & 35 & 92.1 & 77.8 & 21.0 \\
\hline Smoking & Ever & 5 & 12.8 & 3 & 11.8 & 77.1 & 25.3 & 9 & 16.0 & 0 & 0.0 & 0.0 & 0.0 & - & - & 3 & 7.9 & 77.1 & 25.2 \\
\hline & t-test & (P-val & & & 0.01 & $(0.50)$ & & - & & & & - & & & - & & 0.05 & $(0.48)$ & \\
\hline$\stackrel{\mathscr{0}}{=}$ & Never & 14 & 35.9 & 5 & 29.4 & 75.6 & 25.0 & 22 & 39.3 & 11 & 52.4 & 83.0 & 22.6 & -0.57 & 0.29 & 16 & 42.1 & 80.7 & 22.8 \\
\hline $\begin{array}{l}\text { Afcohol } \\
\text { If } \\
\text { intake }\end{array}$ & Ever & 25 & 64.1 & 12 & 70.6 & 78.0 & 21.5 & 34 & 60.7 & 10 & 47.6 & 72.9 & 18.2 & 0.60 & 0.28 & 22 & 57.9 & 75.7 & 19.8 \\
\hline is & t-test & (P-val & & & -0.19 & $(0.43)$ & & - & & & 1.3( & $0.14)$ & & & & & 0.70 & $(0.24)$ & \\
\hline \#Smoking & Never & 16 & 69.6 & 4 & 66.7 & 82.0 & 23.7 & 25 & 64.1 & 11 & 100.0 & 83.0 & 22.6 & -0.07 & 0.47 & 15 & 88.2 & 82.7 & 22.0 \\
\hline and & Ever & 7 & 30.4 & 2 & 33.3 & 90.6 & 13.3 & 14 & 35.9 & 0 & 0 & 0 & 0 & - & - & 2 & 11.8 & 90.6 & 13.3 \\
\hline & t-test & (P-val & & & -0.57 & $(0.30)$ & & - & & - & - & - & - & - & - & & -0.72 & $2(0.28)$ & \\
\hline & Never & 28 & 71.8 & 12 & 70.6 & 79.3 & 18.7 & 37 & 66.1 & 14 & 66.7 & 82.5 & 16.5 & -0.46 & 0.33 & 26 & 68.4 & 81.1 & 17.3 \\
\hline medication & Ever & 11 & 28.2 & 5 & 29.4 & 72.2 & 29.9 & 19 & 33.9 & 7 & 33.3 & 69.4 & 26.6 & 0.17 & 0.44 & 12 & 31.6 & 70.6 & 26.7 \\
\hline & t-test & ?-val & & & 0.49 & $(0.32)$ & & - & & & 1.19 & $(0.13)$ & & & - & & 1.25 & $(0.16)$ & \\
\hline
\end{tabular}

Pearson's bivariate correlations showed that, especially among sub-fertile study subjects, there was a significant but negative correlation between age-group and frequency of MESI $(\mathrm{R}=-0.18$, P-value $=0.04)$ and a marginally significant correlation between ever fathered a child and MESI $(\mathrm{R}=0.199$, $\mathrm{P}$-value $=0.05)$ (Table 6). 
Table 6. Bi-variate correlation coefficient between frequency of ejaculation and specific variables among sub-fertile men.

\begin{tabular}{lcccc}
\hline & \multicolumn{3}{c}{ Frequency of ejaculation } \\
\cline { 2 - 4 } \multicolumn{1}{c}{ Variables } & \multicolumn{2}{c}{ Sperm donors } & \multicolumn{2}{c}{ Sub-fertile men } \\
\cline { 2 - 4 } & Pearson's & P-value & Pearson's \\
Age group & $\mathrm{R}$ & 0.731 & -0.18 & 0.04 \\
BMI group & 0.084 & 0.352 & 0.027 & 0.80 \\
Systolic blood pressure (mmHg) & -0.226 & 0.798 & -0.08 & 0.46 \\
Diastolic blood pressure (mmHg) & 0.063 & 0.290 & 0.03 & 0.74 \\
Type of infertility & 0.256 & - & -0.119 & 0.25 \\
Ever fathered a child & - & - & 0.199 & 0.05 \\
Miscarriage in partner & - & -0.007 & 0.94 \\
Use of Herbal medicinal tea & - & 0.059 & 0.57 \\
Alcohol consumption & -0.004 & 0.985 & 0.052 & 0.62 \\
Number of cigarettes smoked daily & -0.422 & 0.072 & -0.041 & 0.70 \\
DNA fragmentation index & 0.247 & 0.307 & -0.076 & 0.46 \\
\hline
\end{tabular}

\section{Discussion}

Though central to human existence, the issue of daily, weekly or monthly male ejaculations at sexual intercourse has not been a focus on any intense debate or discussion in any forum. This is probably because sexual intercourse, one event in which ejaculation takes place, is taken as a sacrosanct subject by many. It is speculated that, in humans, pregnancy may not occur without sperm being introduced into the female vagina, naturally, through assisted reproduction technology (ART) such as in-vitro fertilization (IVF) or otherwise. This paper is the first to elucidate the frequency of monthly ejaculations at sexual intercourse especially among sperm donors and among sub-fertile Black men in sub-Sahara Africa. Our findings have demonstrated the need for better understanding of the phenomenon of ejaculation at sexual intercourse and its relationship with health. Though literature review did not bring up the frequency of ejaculation at sexual intercourse among sperm donors or sub-fertile men, still there are some key findings in this paper that warrant further discussion. First, sperm donors aged $<40$ years were twice as likely to have very low frequency of monthly ejaculation at sexual intercourse. This might be because sperm donors are young and probably college students who donate sperm for money and once paid there was no need to ejaculate for a while. It might also be that these people are not actually infertile, thus are not looking for a child. As in women, age is also a major factor in male sexuality. Among the sub-fertile men, there was a significant difference in the proportion of men aged $<40$ years $(55.9 \%)$ and those aged $\geq 40$ years who had high (11 - 15) frequency of monthly ejaculations. Also, the mean monthly ejaculation rate was significantly higher in those $<40$ years than among those $\geq 40$ years, a finding that corroborates that of Rider et al. that ejaculation frequency declines with age [12]. Another key finding is that those who had ever 
fathered a child had a lower mean frequency of monthly ejaculation at sexual intercourse compared to those who have never fathered a child. There has been no reported study on the frequency of ejaculation at sexual intercourse among males who had never fathered a child. However, possible reasons for this variation is that those who had never fathered a child might be anxious to get their partner pregnant or, in sub-Saharan setting, might be under pressure to get another wife if the current one does not get pregnant, thus having frequent sexual intercourse. Another reason for this phenomenon is that a vicious cycle is set up as the more frequent the sexual intercourse, the less the semen volume, sperm count and sperm concentration, to an extent [13] [14].

Although the difference was not statistically significant, however, this study reports a gradual decline in systolic blood pressure among men 40 years and older. This is a novel finding in sub-Saharan Africa. Many studies reported the health benefits of moderately high frequency of ejaculation to reduce the risk of prostate cancer but here we report the health benefits in reducing systolic blood pressure. The explanation for the mechanism of this apparent reduction in systolic blood pressure is probably complex, though we suspect it may have to do with the hypothalamus, the vagus nerve, or probably the renin-angiotensin mechanism. More studies are required to illuminate this phenomenon. Since studies on this topic are very rare, internet search article reports surprising health benefits of sex (ejaculation) one of which is lowering blood pressure, although the article quickly says that sex sessions (presumably with ejaculations) cannot replace blood-pressure lowering drugs to control high blood pressure, but may be a useful addition [15].

Our findings also show that the mean frequency of ejaculations at sexual intercourse was significantly higher among men who never smoked cigarette compared to those who had ever, though the difference was not statistically significant. This agrees with the findings of Kovac et al. [16] and Millett [17] that there is a relationship between cigarette smoking and erectile dysfunction (ED) which is dependent upon the parasympathetic nervous system, that induces smooth muscle relaxation allowing arterial blood into the corpus cavernosum via the actions of nitric oxide (NO) [18]. Nitric oxide (NO) is generated by three nitric oxide synthase (NOS) enzyme isoforms: neuronal, endothelial and inducible. The neuronal isoform appears to be the primary mediator of physiologic erection [19]. Neuronal NOS activity by non-adrenergic non-cholinergic neurons is known to be decreased in both in vitro and in vivo models of smoking [20]. It has been well-established in the vascular literature that cigarette smoking damages the endothelium and impairs endothelial NOS mediated vasodilation [21] [22] [23].

Finally, fertilization rate was significantly higher in younger sub-fertile men who proceeded to IVF. This accords with the findings of Humm and Sakkas who reported similar findings [23]. One of the possible explanations for this is what Esbert et al. reported that sperm DNA fragmentation in older men might have a detrimental outcome on IVF with own or donated oocyte [24]. 


\section{Conclusion and Recommendations}

To conclude the part 2 of this paper, we studied sperm donors and sub-fertile men presenting at our clinic for infertility problems. In the general population, over $50 \%$ of men whose age is $>40$ will have some varying degree of erectile dysfunction or ED [17]. In this study, sub-fertile men aged $\geq 40$ years were about 2 $1 / 2$ times more likely to have very low frequency of MESI when compared with younger sub-fertile men. Overall, systolic blood pressure $(\mathrm{mmHg})$ declined gradually as frequency of MESI increased, though there was no perceptible statistical significance in the observed decline. While sub-fertile men aged $\geq 40$ with systolic hypertension $(\geq 140 \mathrm{mmHg}$ ) were about $21 / 2$ times more likely to have low frequency of MESI, those with diastolic hypertension ( $\geq 90 \mathrm{mmHg}$ ) were approximately 6 times more likely to have low frequency of MESI. The overall mean fertilization rate among sub-fertile men aged $<40$ was significantly higher than that among older sub-fertile men. Cigarette smoking, more than alcohol consumption, appears to be a major factor that significantly affected the frequency of MESI among sub-fertile men in all age groups. Frequency of monthly ejaculations at sexual intercourse negatively but insignificantly correlated with systolic blood pressure. Clinicians, Urologists and Gynecologists should counsel their patients who present for male infertility on not only alcohol consumption and cigarette smoking habits but also on control of blood pressure. They should also educate their patients on factors that could contribute to the fragmentation of their sperm DNA and the effect of this on the possibility of them fathering a child.

\section{Study Limitations}

This study has some strengths and weaknesses. Concerning strength of the study, semen collection was very accurate and laboratory analysis of seminal fluid and DNA fragmentation were conducted using modern equipment and according to the latest WHO standard. However, the sample size was small and there could have been a bias in sampling. The study subjects were not representative of the general population thus the data should not be extended to the generality. Further, the study was facility-based and does not reflect the frequency of monthly ejaculations at sexual intercourse of normal heal thy male in the community. Furthermore, there were no underweight men with BMI $<18.5 \mathrm{~kg} / \mathrm{m}^{2}$ in the study which could have made the data more robust. In addition, this study did not take into consideration men with erectile dysfunction syndrome which may be a factor in low frequency of ejaculation among the sub-fertile men. Finally, we did not study the dose-dependence relationship between cigarette smoking and MESI, alcohol consumption and MESI and combined cigarette smoking plus alcohol consumption and MESI.

\section{Acknowledgements}

Special thanks go to our patients. 


\section{Conflicts of Interest}

The authors declare no conflicts of interest regarding the publication of this paper.

\section{References}

[1] Robaire, B., Hinton, B.T. and Orgebin-Crist, M.-C. (2006) The Epididymis. In: Neill, J., et al., Eds., Knobil s Physiology of Reproduction, Vol. 1, Elsevier, New York, 1071-1148. https://doi.org/10.1016/B978-012515400-0/50027-0

[2] Harvard Health Publishing. Ejaculation Frequency and Prostate Cancer. http://health.harvard.edu/

[3] Courtois, F.J., Charvier, K.F., Leriche, A., Vezina, J., Cote, M. and Belanger, M. (2007) Blood Pressure Changes during Sexual Stimulation, Ejaculation and Midodrine Treatment in Men with Spinal Cord Injury. BJU International, 101, 331-337. https://doi.org/10.1111/j.1464-410X.2007.07254.x

[4] Castleman, M. Eight Reasons Sex Improves Your Health. http://aarp.org/

[5] American Urological Association 2015 Annual Meeting. https://www.medscape.com/viewarticle/844820

[6] Leitzmann, M.F., Platz, E.A., Stampfer, M.J., et al. (2004) Ejaculation Frequency and Subsequent Risk of Prostate Cancer. JAMA, 291, 1578-1586. https://doi.org/10.1001/jama.291.13.1578

[7] Alexander, B. (2004) Not Just Good, but Good for You. https://www.nbcnews.com/

[8] Abayomi, B.A., Afolabi, B.M., Victor, D.A., Oyetunji, I., et al. (2018) Semen Parameters Associated with Male Infertility in a Sub-Saharan Black Population: The Effect of Age and Body Mass Index. Journal of Gynecology and Infertility, 1, 1-8.

[9] World Health Organization (2011) WHO Laboratory Manual for the Examination and Processing of Human Semen. 5th Edition, World Health Organization, Geneva.

[10] Ajayi, A.B., Afolabi, B.M., Ajayi, V.D., Oyetunji, I.O., Atiba, A., Saanu, S., Adeoye, A.T., Adeshida, T.E., Ehichioya, J. and Ayelehin, I.I. (2018) Evaluation of Sperm DNA Fragmentation amongst Infertile Black Africans. A Nigerian Study. Open Journal of Urology, 8, 297-316. https://doi.org/10.4236/oju.2018.811034

[11] Ajayi, A.B., Afolabi, B.M., Ajayi, V.D., Oyetunji, I.O., Atiba, A., Saanu, S., Adeoye, A.T., Ehichioya, J. and Ayelehin, I.I. (2019) Frequency of Monthly Ejaculation at Sexual Intercourse, DNA Fragmentation Index and Fertilization Rate among Sperm Donors and Fertility-Challenged Men in Sub-Saharan Africa: Paper 1. Open Journal of Urology, 9, 181-194. https://doi.org/10.4236/oju.2019.911021

[12] Rider, J.R., Wilson, K.M., Sinnott, J.A., Kelly, R.S., Mucci, L.A. and Giovannucci, E.L. (2016) Ejaculation Frequency and Risk of Prostate Cancer: Updated Results with an Additional Decade of Follow-Up. European Urology, 70, 974-982. https://doi.org/10.1016/j.eururo.2016.03.027

[13] Levin, R.M., Latimore, J., Wein, A.J. and Van Arsdalen, K.N. (1986) Correlation of Sperm Count with Frequency of Ejaculation. Fertility and Sterility, 45, 732-734. https://doi.org/10.1016/S0015-0282(16)49352-0

[14] Welliver, C., Benson, A.D., Frederick, L., Leader, B., Tirado, E., Feustel, P., Kontio, J., McAsey, M. and Kohler, T.S. (2016) Analysis of Semen Parameters during 2 Weeks of Daily Ejaculation: A First in Humans Study. Translational Andrology and Urology, 5, 749-755. https://doi.org/10.21037/tau.2016.08.20

[15] Stoppler, M. The Surprising Health Benefits of Sex. 
https://www.onhealth.com/script/main/hp.asp

[16] Kovac, J.R., Labbate, C., Ramasamy, R., Tang, D. and Lipshultz, L.I. (2015) Effects of Cigarette Smoking on Erectile Dysfunction. Andrologia, 47, 1087-1092. https://doi.org/10.1111/and.12393

[17] Millett, C., Wen, L.M., Rissel, C., Smith, A., Richters, J., Grulich, A. and de Visser, R. (2006) Smoking and Erectile Dysfunction: Findings from a Representative Sample of Australian Men. Tobacco Control, 15, 136-139.

https://doi.org/10.1136/tc.2005.015545

[18] Rajfer, J.A.W., Bush, P.A., Dorney, F.J. and Ignarro, L.J. (1992) Nitric Oxide as a Mediator of Smooth Muscle Relaxation of the Corpus Cavernosum in Response to Nonadrenergic Noncholinergic Neurotransmission. The New England Journal of Medicine, 326, 90-94. https://doi.org/10.1056/NEJM199201093260203

[19] Burnett, A.L. (1995) Nitric Oxide Control of Lower Genitourinary Tract Functions: A Review. Urology, 45, 1071-1083. https://doi.org/10.1016/S0090-4295(99)80136-8

[20] Xie, Y., Garban, H., Ng, C., Rajfer, J. and Gonzalez-Cadavid, N.F. (1997) Effect of Long-Term Passive Smoking on Erectile Function and Penile Nitric Oxide Synthase in the Rat. The Journal of Urology, 157, 1121-1126.

https://doi.org/10.1016/S0022-5347(01)65153-X

[21] Celermajer, D.S., Sorensen, K.E., Georgakopoulos, D., Bull, C., Thomas, O., Robinson, J. and Deanfield, J.E. (1993) Cigarette Smoking Is Associated with Dose-Related and Potentially Reversible Impairment of Endothelium-Dependent Dilation in Healthy Young Adults. Circulation, 88, 2149-2155.

https://doi.org/10.1161/01.CIR.88.5.2149

[22] Butler, R., Morris, A.D. and Struthers, A.D. (2001) Cigarette Smoking in Men and Vascular Responsiveness. British Journal of Clinical Pharmacology, 52, 145-149. https://doi.org/10.1046/j.0306-5251.2001.01434.x

[23] Humm, K.C. and Sakkas, D. (2013) Role of Increased Male Age in IVF and Egg Donation: Is Sperm DNA Fragmentation Responsible? Fertility and Sterility, 99, 30-36. https://doi.org/10.1016/j.fertnstert.2012.11.024

[24] Esbert, M., Pacheco, A., Vidal, F., Florensa, M., Riqueros, M., Ballesteros, A., Garrido, N. and Calderón, G. (2011) Impact of Sperm DNA Fragmentation on the Outcome of IVF with Own or Donated Oocytes. Reproductive BioMedicine Online, 23, 704-710. https://doi.org/10.1016/j.rbmo.2011.07.010 


\section{Abbreviations}

ANOVA: Analysis of variance

BMI: Body Mass Index

CI: Confidence interval

DFI: DNA fragmentation index

DNA: Deoxyribonucleic acid

ED: Erectile dysfunction

MESI: Monthly ejaculation at sexual intercourse

NFC: Nordica Fertility Center

OR: Odds ratio

ROS: Reactive oxygen species

SD: Sperm donors

sd: Standard deviation

SFM: Sub-fertile men

TTC: Years trying to conceive

WHO: World Health Organization 